\title{
Prolonged Coresidence: Difficulties and Benefits of Israeli Arab Emerging Adults Who Live with Their Parents
}

\author{
Asnat Dor ${ }^{1}$, Hana Hallifa-Yunnis ${ }^{2}$ \\ ${ }^{1}$ Department of Education, Emek Yezreel Academic College, Emek Yezreel, Israel \\ ${ }^{2}$ Department of Education, Emek Yezreel Academic College, Emek Yezreel, Israel \\ Correspondence: Asnat Dor, Department of Education, Emek Yezreel Academic College, Emek Yezreel, Israel.
}

Received: October 26, 2016

Accepted: November 8, 2016

Available online: November 16, 2016

doi:10.11114/ijsss.v4i12.1986

URL: http://dx.doi.org/10.11114/ijsss.v4i12.1986

\begin{abstract}
This qualitative study focuses on Israeli Arab emerging adults who live at home with their parents, and explores their experience as to the benefits and difficulties of prolonged coresidence. Semi-structured open interviews were conducted with 16 Arab emerging adults ( 8 women, 8 men), who live at home with their parents. Findings reveal that most participants live with their parents out of respect to cultural norms. While doing so they experience amb ivalence: The benefits are family support and convenient living conditions, the difficulties include living according to social expectations, dealing with parents'criticism, and is sues related to the generation gap.

It's appears that the Arab emerging adults are making their way in a changing society, and a great deal of their obstacles at home with their parents is related directly to a society in transition.
\end{abstract}

Keywords: emerging adults, culture, generation differences, family relations, Intergenerational relations, a society in transition

\section{Introduction}

\subsection{Emerging Adults and Their Parents}

In childhood and adolescence, parents are the figures of authority and influence, an asymmetrical pattern that tends to shift and become more reciprocal, equal, and symmetrical as the children approach adulthood (Buhl 2007; Tanner 2006). In most cases, the turbulence of adolescents eases as adolescents move into emerging adulthood. Once stormy parent-child relationships become more stable and closer, communication begins to flow more freely, and reciprocity increases as conflicts subside (Aquilino,1997; Lefkowitz 2005; Morgan, Thorne, and Zurbriggen 2010; Van Wel, Ter Bogt, and Raaijmakers 2002). Bipartisan learning begins, as parents become acquainted with a new autonomous individual (Aquilino 2006), and children meet their parents as individuals with their own needs, weaknesses, and life histories (Aquilino 2006; Birditt, Fingerman, Lefkowitz, and Kamp-Dush 2008; Vassallo, Smart, and Price-Robertson 2009; Youniss and Smollar 1985).

As any learning process, this meeting of parent and child as adults does not always follow a smooth course, and conflicts - at time reminiscent of those of the child adolescent years - may develop (Clarke, Preston, Raksin, and Bengtson 1999). While such conflicts tend to subside as the children enter adulthood and move out of the parents' home (Berman and Sperling 1991; Buhl 2007), when the young adults are financially dependent on the parents, and especially if they are still living with the parents, relationships may be tense (Aquilino 2006; Vassallo et al. 2009).

\subsection{Emerging Adult's Residential Status}

On this prolonged journey - as they continue to search for self-identity - emerg ing adults (age 18-30) lack stability and defer assuming long-term personal and professional commitments. They may not be steadily employed, and delay marriage, parenthood, and professional and career decisions (Arnett 2000, 2001, 2004; Juang and Silbereisen 2001; Shulman and Ben-Artzi 2003; Shulman, Feldman, Blatt, Coken, and Mahler 2005). Increasingly, emerging adults continue to live with their parents (Arnett 2001, 2004; Aquilino 2006; Settersten and Ray 2010; Vassallo et al. 2009), reaching rates of 50\% and more in Europe and the United States (Coleman and Brooks 2009; Kloep and Hendry 2010; U.S. Census Bureau 2011). The reasons for remaining at the parents' home are varied - studies, high cost of living, and convenience as well as parental separation anxiety (Kins, Soenens and Beyers 2011), or separation-individuation 
problems (Kins et al. 2011; Kloep and Hendry 2010).

Leaving home has been seen as an important component of entering adulthood is Western society, but not the sole indication of achieving their self-developmental tasks (Kins et al. 2011; Yanir 2007). The reasons for the emerging adult's residential status should be examined and noted, and not taken as a sign of success or failure in managing developmental tasks Kins et al. 2011). In addition, while "there are cultural differences in expectations and traditions of young people leaving home and becoming independent" (Kloep and Hendry 2010, p. 818), remain ing in the parents' home affects parent-child relationships. According to Dubas and Peterson (1996), 21 -year-old adults, who live with their parents or not far from them, reported having poorer relationships with their parents than their counterparts who had moved out and away. The old adage that distance makes the heart grow fonder is supported by research: Aquilino (1997) found that transition to college, full-time employ ment, and cohabitation or marriage, were associated with closer, more supportive, and less conflicted parent-child relationships.

It is child's life circumstances that determine parent-child relationships (Furstenberg 2010) and these relations are better when children, as emerging adults residing with their parents, study, work, or seek employment, than when they struggle with independence. In all cases, this living situation requires both parties to adjust to new patterns of interaction to meet everyone's needs and demands (Yan ir 2007), at the time when parents must deal with the changes and challenges of midlife and begin facing their own ag ing (DeVries, Kerrick, and Oetinger 2007). This is also the time when parents may have to deal with disappointment of realizing that they did not - nor will they - reach all their goals. Death and illness of their contemporaries become part of the parents' reality, along with their own slowing down physically and changes in sexual drive (Colarusso and Nemiroff 1987). At the same time, many continue to work full time, and may be combining employ ment with caring for their children and their own parents, and perhap s also helping out with grandchildren (Fingerman, Pitzer, Chan, Birditt, Franks, and Zarit 2011; Gautun and Hagen 2010).

The role of parents to emerging adults is ambivalent, with parents in their fifties or sixties learning to handle young people's prolonged dependency or watching their children leave home (Hendry and Kloep 2007). The parents' reaction, in both cases, affects their own psychological adjustment and their future relationships with their adult children (Kloep and Hendry 2010). Bouchard (2014) refers to the effects of the children's departure on parental well-being. In her essay she refers to studies that have conceptualized parental well-being in terms of parents' marital quality, marital equity, relations with the children, physical and psychological well-being. The role loss perspective (the empty-nest stage and the absence of alternative roles which could lead to decrease in parental well being) and the role strain perspective (the empty-nest stage might lead to improvement in parental well-being) are also presented (Bochard 2014). In a study of parents' perspectives and experiences regarding mutual acco mmodation with an emerging adult offspring, Dor (2013) found parental ambivalence: On the one hand, parents enjoy the mutual time and the ma ture relationship with their child. On the other hand, they have to deal with conflicts, financial difficulties, and lack of privacy, rendering this extended active parental role a difficult one at times.

\subsection{Emerging Adults in Israel: The Arab Population}

Israel, where the present study was conducted, is a multiethnic and multinational state, composed of a multitude of subcultures and groups with a wide variety of social backgrounds. The largest ethnic group (about 80\%) is Jewish, and it, too, includes subgroups of immigrants from all parts of the world. On the whole, the Jewish population can be characterized as a modern society with a Western orientation. Another large group in Israeli society (about 20\%) is Arab, mostly Muslim, and is characterized as a traditional collectivist, conservative society, with a higher level of commitment to group and family values. Thus, Israeli society hosts, side by side, values and principles representing modern Western culture and those representing traditional culture (El-Haj' 1984). In the traditional Arab family, marriage is perceived as a means toward adulthood and responsibility. Parents urge children in their early twenties to marry and adopt an adult lifestyle, even as they continue to live nearby - married couples are expected to live close to the husband's family. In addition to being the door to adulthood, marriage is believed to be a mechanism that prevents undesired social behaviors and controls them (Abu Baker 2012). At the same time, since the late 1980s, young Israeli Arabs have been marrying later than before (Central Bureau of Statistics 2015), similar to young secular Israeli Jews and to trends in the Western world. Nonetheless, a comparis on of the average age of marriage in the Arab population in Israel with that of the Jewish secular population, reveals that the Arabs are still younger when they are marry (26.5 for men and 21.2 for wo men) that Jews (28.3 for men, 25.9 for wo men; Gharrah 2013). While this change is noticeable, and while its pace is slower than in Jewish society, it is bringing about a softer approach to the traditional authoritative and hierarchical structure of Arab families in Israel.

Unlike their Je wish peers, young Arabs are exempt from military service. Therefore, at age 18, Israeli Arab high-school graduated seek employment or pursue higher education, so that when they graduate they are 5-6 years younger than their Jewish counterparts who served for 2-3 years in the military and often take a long journey after their discharge. 
Hence, it is possible that the difference in marriage age derives not only from cultural and traditional values, but is also due to the difference in the social duties of Jews and Arabs.

\subsection{Research Scope and Objectives}

The term emerg ing adulthood usually refers to modern, Western society. However, due to the Western influence on the Arab society in Israel, it is recommended to study the way those influences are expressed among Israeli Arabs. As stated above, young Arabs are expected to live with their parents until they marry, but due to social changes are more open to modern Western influences, and do not always act according to tradition. The present study is an attempt to expand knowledge about Israeli Arab emerging adults' views and their experiences in regard to their living with their parents in the parents' homes. This study will explore how they feel about living with their parents and what they consider to be the benefits and difficulties of the situation. The research tool was a three-question semi open questionnaire, based on a research protocol which was designed to deepen our understanding of the experience of parents who live with their emerg ing adult offspring (Dor 2013). The original questionnaire focused on the parents' point of view, and for this s tudy, the questions were adapted to reveal the way Israeli Arab emerging adults feel and handle this period in their lives.

\section{Method}

\subsection{Participants}

The participants in this qualitative study were 16 un married emerging adult Israeli Arabs ( 8 wo men, 8 men) who lived in their parents' home in northern Israel. The participants were $20-30$ years old $(M=26.60, S D=2.77)$, of middle socioeconomic class, all matriculated high-school graduates. They all had siblings, with an average number of 4.25 children per family ( $\mathrm{SD}=1.54)$. Three of the participants were firstborn, and eight were the youngest in the family. Eight participants $(50 \%)$ had their own room in their parents' house, the others shared a room with a sibling. While pursuing their studies (BA - 6 participants, MA - 2, MD - 1) they had lived away from home for 3-4 years, and returned after graduation. Three were about to start their academic education, two were unsure about their future plans regarding learning and one was certain that he is not going to pursue higher education. Three were from divorced families, the parents of the other participants were married to

each other. Most participants (14) were employed - one was a doctor, another an accountant, and the other 12 held part-time positions in fast food chains, customer service, or sales.

\subsection{Sampling Method, Procedure, and Data Collection}

The snowball method, beginning with the researchers' connections, was used to reach participants for this study. The initial inquiry yielded 3 participants, who referred the researchers to the other 13 participants. Participation was voluntary, and participants were guaranteed confidentiality, and were also told that they could withdraw from the study at any stage. All 16 participants signed a consent form of participation in the study. Most of the one-on-one, 45-70 minute interviews took place in the participants' homes, at their convenience, two interviews took place in a restaurant, and one in the home of one of the researchers house. The intervie ws were audio recorded with participants' permission. Pseudonyms were assigned to maintain anonymity.

\subsection{Research Instrument and Data Analysis}

The research tool chosen for this qualitative study was a semi-structured open interview, a tool that enables interviewees to expand and clarify their answers and to give examples. The interviews followed a three-question research protocol (Dor, 2013), aimed at exploring the emerging adults' feelings and experiences relating to living with their parents. The questions were: (1) Generally speaking, how would you describe your feelings about living at home? (2) Are you coping with any difficulties that are directly related to your living at home? (3) Are there any benefits or advantages to living at home? All participants answered all questions, and in some cases gave more than one answer.

A thematic analysis (Braun and Clarke 2006; Sandelowski and Barroso 2003) was used to analyze the interviews, with the aim being to derive distinct themes regard ing each of the questions. To establish thematic reliability, two researchers began by separately searching for systematic, recurring, visible, and direct content; they referred back to this content by frequency of appearance and their interpretation of their significance to the interviewees. During the interpretation process, the researchers divided the content (which they had agreed upon) into groups, identified prominent themes, and named each theme.

\section{Results}

The findings were analy zed according to their content. As the analysis revealed overlapping points and similarities, the theme derived from Question 1 (general feelings) are combined with those of the other two questions. The themes are listed in the order in which the questions were asked. The themes derived are presented, by participant's gender, in Table 1 . 
Table 1. Themes Identified in each of the Three Questions (by gender)

\begin{tabular}{|c|c|c|c|}
\hline Question & Theme & Women $\mathrm{N}=8$ & Men $\mathrm{N}=8$ \\
\hline & Lack of privacy & 4 & 4 \\
\hline & $\begin{array}{l}\text { Dealing with parents' } \\
\text { criticis m }\end{array}$ & 4 & 6 \\
\hline \multirow[t]{3}{*}{$\begin{array}{l}\text { General feelings and } \\
\text { difficulties }\end{array}$} & $\begin{array}{l}\text { Need to conform to } \\
\text { social expectations }\end{array}$ & 8 & 6 \\
\hline & Generational gap & 3 & 4 \\
\hline & Family support & 7 & 7 \\
\hline \multirow{2}{*}{$\begin{array}{l}\text { General feelings and } \\
\text { benefits }\end{array}$} & Convenience & 3 & 6 \\
\hline & $\begin{array}{l}\text { Ability to help the } \\
\text { family }\end{array}$ & 7 & 4 \\
\hline
\end{tabular}

Note: Most of the interviewees suggested more than one theme per question.

\subsection{Themes Derived from Question 1+ 2}

As seen in Table 1, these questions yielded four main the mes: Lack of privacy ( 4 wo men,, 4 men); Dealing with parents' critic is m (4 wo men, 6 men); Need to conform to social expectations ( 8 wo men, 6 men); Generational gap (3 wo men, 4 men).

\subsubsection{Lack of Privacy}

Some of the issues related to lack of privacy were the need to attend family gatherings, intense parents' interfering in the emerging adult's life, and having to update parents on everyday activities.

There is no privacy. They want to know everything about me. I don't like it. I need my space. Also in phone call with whoever I want to talk to. They think that as long as I live at home I have to report on every action I do (woman, 26).

Some emerging adults who live with their parents have to share a room with another - usually younger - sibling. This arrangement means that they have to deal with all the ramifications of a shared territory including arguments with the sibling. They cannot always invite friends home at their own convenience, and often have to consider other family members' needs.

\subsubsection{Dealing with Parents' Criticism}

Participants, who do not fulfill parents' expectations, feel that they disappoint their parents and have to deal with the parents' criticism:

My parents want for me things that I can't relate to. They want me to be married although I'm not in a relationship. It's like they want me to be someone else. We had many talks about my future plans which are different than theirs. I have no energy left for any more talks (woman, 27).

Parents have expectations that may never be fulfilled, and this situation may evoke negative feelings in both sides and create tension and uneasiness. Most of participants' examp les related to what their parents' wishes regarding their adult child's life style, future plans, and starting a family. When the participants did not have the same roadmap for their life, parents became stressed and critical.

\subsubsection{Need to Conform to Social Expectations}

In addition to living with their parents' expectations, Arab Israeli emerging adults experience social and cultural restrictions. Being a part of a relatively conservative society, their awareness of social expectation may make them feel restricted, resulting in limited - or even avoiding - experiences and explorations:

I feel limited. Although I want to live with my girlfriend before marriage, I feel I can't do it. It's against social norms. I don't feel I can do it. Too many people can be hurt, so I behave according to expectations (man, 24).

It seems that in some cases emerg ing adults are a ware of their own avoidance of acting differently or according to their own wishes. They are aware of the huge influence that society has on them, in a way that it determines the way they behave and the decisions they make. 


\subsubsection{Generational Gap}

Among Israeli Arabs, exposure to Western norms and values has affected their own traditional norms and values. These effects are especially perceived among the younger generations. While the parents' generations have not been swept with the last technological, cultural, digital changes, their children may have very well have:

There are gaps. The parents had a different life. Our life is faster, more tense than theirs. We are more open to technology and to Western culture. We don't visit the extended family as often as they did. We are more involved in our own affairs (woman, 27).

These differences create tension between parents and their children. As the emerg ing adults are more open to academic education and to technological changes, more occupational options are open for them. All this may create distance and different life perspectives, between them and the parents'generation.

\subsection{Themes Derived from Question 1+ 3}

In General, How Would you describe Your Feelings about living at Home? Are there any benefits or advantages you experience that accompany your living at home?

As can be seen in Table 1, three main themes were identified regard ing these questions: Family support (7 wo men, 7 men); Convenience ( 3 women, 6 men). Ability to help the family ( 7 women, 4 men).

\subsubsection{Family Support}

Different kinds of support were described by the participants, regarding their living with their parents. The emerg ing adults described emotional support and financial and practical everyday help:

I live with my supportive family. In every crisis, they are right by my side. I have someone who listens to me and cheers me up (man, 24).

I better stay at my mother's house for now, all my expenses are covered (man, 25).

It seems that the financial aspect was significant to most participants, with the high cost of living driving them into delaying coping with daily life by on their own. Also, the answers revealed a sense of security gained by living with the parents at this stage of life. The participants described the way they trusted their parents to be there for them in all cases.

\subsubsection{Convenience}

Emerging adults who live with their parents spoke about the fact that all house chores are done by other members in their family. The participants were not responsible for any chores, although they (especially the women) helped occasionally when their parents asked. This position was very comfortable for them, as it allowed them to postpone responsibilities, which they knew, they would have to assume in the future, once they have their own family:

I live with my parents' so I don't have to cook, to do my laundry, etc. Everything is being taken care off (man, 30).

I don't have to worry about a thing (man, 27).

Bills are paid, cleaning, cooking, everything is done (man, 26).

It seems that this position is comfortable for some of the participants. They are delaying their need to provide for themselves, relying instead on their parents to provide them with everything they need.

\subsubsection{Ability to Help the Family}

Some of the participants described a benefit in relation to their ability to help their parents at that stage. While they lived at home they valued the fact that they were close to their parents, knew everything that happens in the house, and were able to give a hand when needed:

If I'm away from my parents, it's hard for me to be away from everything that happens at home. This way it's much easier for me to help my mother in case she is sick (woman, 25.

It seems that giving help and making life easier for family members is also significant in the eyes of some of the participants and they value it as a benefit of living in their parents' house. They value their ability to contribute to their parents at this stage and they see the benefits that come along with their delayed home leaving.

\subsection{Summary of the Research Finding}

Overall, 13 of the 16 participants ( 8 women and 5 men) in this study experienced ambivalence as they reported both positive and negative responses. Along with convenience, no financial worries, and family support at home, they coped with lack of privacy, parents' criticis $m$, a generational gap, and social expectations. Three of the 16 respondents (all three were men), expressed only positive responses in regard to their living with their parents. The emerging adults we 
interviewed - men and wo men alike - were similar in the frequency of most themes, except for the the mes Convenience (more frequent among men than among women) and Ability to help the family (more frequent among women than among men).

\section{Discussion}

This qualitative study aimed to explore the difficulties and benefits of Israeli Arab emerg ing adults who live with their parents.

Semi-structured open interviews were conducted with 16 Israeli Arab emerging adults. Findings reveal that most of the participants experienced ambivalence: While noting family support and the living and financial convenience, the participants mentioned the inconvenience in handling the generational gap, especially their parents' criticis $m$ and the need to live according to social expectations. As mentioned earlier, the Arab society in Israel in general is traditional, reflecting more patriarchal, collectivist, and conservative values (Dwairy and Achoui 2006). According to the traditional norms of Arab society, young people are subordinate to the old and according to patriarchal norms, all family members obey the father's authority (Barakat n.d.).

At the same time, so me researches (Dwairy 1998; Sarugy 2000) refer to the influence of living side by side with modern Western society, noting that family values and traditionalis $m$ have been affected by the Western values of individualis $m$ and liberalism. Gradually, since the 1990s, Israeli Arabs are becoming exposed to liberal, individualist values, with a tendency toward gender equality, values that are prevalent in overall Israeli society (Dwairy and Achoui 2006). As they express a more Western individual orientation, the age of marriage has been delayed among young Israeli Arabs as in the entire Western world, they are likely to speak two or three languages, have academic education and profes sions, are more mobile and feel less obliged to live at their parents' home (as traditionally expected). They might live in Jewish towns or mixed Jewish-Arab towns (Abu Baker 2012). This generation of young, educated professional includes wo men who have broken away from tradition and do not live in their parents' home before marriage. These women create new conventions as they fulfil their wish to pursue education and career. They share apartments with other women their age, who probably have the same aspirations (Abu Baker 2012).

Overall, young Israeli Arab emerging adults who live in urban areas are slowly beginning to show more similarity to young people in Western countries, compared to their rural contemporaries. The higher their social status and the more secular their life style, the higher the tendency to be influenced by Western values (Abu Baker 2012).

Another slow and gradual process is the shift, among young Is raeli Arabs, from the tradition of re lating to individuals in accordance with their family of birth, and not through their personal achievements. Traditional values which glorify conformity and social norms are beginning to take second place to values such as individuation, autonomy, and uniqueness (Abu Baker 2012; Dwairy and Achoui2006; Smooha 1984).

Consequently, the differences between the generations is growing and becoming more prominent. In the case of the young unmarried who live with their parents, the physical proximity causes inconvenience and arguments between the generations, as emerging adults might have other plans or other perceptions regarding this period. The parental role with young adults also seems ambiguous as it not accompanied by clear expectations as to how much involved parenting is expected at this point. It seems however, that in the current study, the respondents still live with their parents out of respect to their parents' expectations and to social norms. The process of modernization and westernization which drives in some cases emerging adults not live in their parents'home before marriage, is still rather gradual.

The is sue of a society in a process of change is even more emphasized when comparing the difficulties mentioned by the Israeli Arab emerging adults who live with their parents with those of their Israeli Je wish counterparts (Dor 2015). While the Arabs refer to personal difficulties that are related to the social level (generational gap and social expectations), as well as to difficulties on the personal level (criticism and lack of privacy), their Jewish counterparts were only focused on difficulties on the personal level: lack of privacy, arguments with the parents over financial is sues and future planning, and not liking their parents' expectations that they do home chores (Dor 2015).

In other words, as much as emerging adults from these two groups experienced difficulties while living with their parents, the focus in each of these groups is substantially different: While the Jewish emerg ing adults deal with personal, self-centered issues, the Arabs are making their way in a changing society, and a great deal of their obstacles at home with their own parents are related directly to a society in transition. It is most likely that the generational gap is deeper among Arabs. The change that the young people are going through as they incorporate Western-liberal values into their lives, may deepen the generational gap, as these changes may be difficult for the older generation to accept (Mohamed and Yusuf, 2011). While several researchers (Arnett 2001, 2004; Aquilino 2006; Settersten and Ray 2010; Vassallo et al. 2009) showed that tense relations between parents and their adult children come to the fore when young adults continue to live with their parents, the mutual accommodation itself is not the reason for that tension in the Israeli Arab families. 
The fact that the emerg ing adults still live with their parents derives in many cases from the social expectation itself - to stay at the parents' house until marriage. The criticis $m$ they experience from their parents is mostly related to values and accepted behavior, among them criticism of the very fact that they delay marriage.

An interesting question relates to the age of the parents - some of whom are in their late forties or early fifties. If so, why is there such a sharp generational gap? By Western standards, people born in the mid-1960s are not considered old. It is possible that as it is a society in transition, the generational gap is much more evident among Israeli Arabs: In the parents'generation, women's status in the family hierarchy is still rather low and they are still expected to submit to their husbands, parents-in-law, and parents (Cohen and Savaya 2003; Haj-Yahia 1997). This generation of parents still has a high rate of unemployed and unprofessional women who, like their mothers, make themselves available to help their child ren by caring for the grandchildren so that their daughters or daughters -in-law can study or work (The Israel democracy institute 2011). Although in some aspects, they support new values of progress and modernization, in others, especially when it concerns them personally, it is more natural for them to relate to old values. It is likely that in the next generations, when nowadays-young women will get older, the generational gap will be less prominent.

Among the benefits of living with parents that the participants repeated were family values. They spoke about the support they got from their family and the financial and daily convenience that comes with it as bene fits, yet 11 of the 16 participants referred also to their being at the parents' house as a benefit, as it made it possible for them to help their parents when needed. Being available to their parents was something they valued and cherished. The issue of assisting family, was also gendered - nearly all Arab female respondents noted this, comparing to only half of male respondents. Also the theme Convenience was more frequent among men comparing to women, as it seems that while living in the parents' house, young men are less required to participate in house chores. This is another way that expresses traditional values, conformity and social norms that are still in the hurt of the changing Arab family. Generally speaking it seems that Israeli Arab emerging adults regard being able to help - both the nuclear family and the extended family - as a great advantage of living with the parents (Abu Baker 2012). Hence, as much as the Arab society in in a transition and is facing accelerated changes, traditional values are accompanied by more modern ones. The emerging adults are paving their way in a changing society, express modern liberal Western values, while at the same time consider the old values that still count in their families.

\subsection{Research Limitations}

Although this is a qualitative study, the relatively s mall sample dictates caution as to the extent to which we can generalize these findings to the entire Israeli Arab population. Second, this is a sensitive and personal issue, and it is possible that not all participants felt comfortable enough to speak openly and may have held back during the interviews. A third limitation is socioeconomic - the interviewees were all middle-class people, and it is likely that interviews with participants in different areas, and from different social backgrounds within Israeli Arab society, might have led us to other results and insights. At the same time, as participation was voluntary, it seems safe to assume that the participants were honest in their answers. The ir authentic voices are a main contribution of the current study, which sheds new light on of the experience of emerging adults, in a minority society in transition, as they find their way on the path to independent adulthood.

\section{References}

Abu Baker, H. (2012). The Palestinian family. In R. A mir (Ed.) Arab Society in Israel: A social mosaic, ethnicity, family, gender, II, 155-270. Raanana, Israel: Open University (Hebrew).

Aquilino, W. S. (1997). From adolescent to young adult: A prospective study of parent- child relations during the transition to adulthood. Journal of Marriage and the Family, 59, 670-686. http://dx.doi.org/10.2307/353953

Aquilino, W. S. (2006). Family relationships and support systems in emerg ing adulthood. In J. J. Arnett \& J. L. Tanner (Eds.), Washington, DC: American Psychological Association, Emerging adults in America: Coming of age in the 21 st century, 193-210. http://dx.doi.org/10.1037/11381-008

Arnett, J. J. (2000). Emerging adulthood: A theory of development from the late teens through the twenties. American Psychologist, 55, 469-480. http://dx.doi.org/10.1037//0003-066X.55.5.469

Arnett, J. J. (2001). Conceptions of the transition to adulthood: Perspectives from adolescence through midlife. Journal of Adult Development, 8, 133-143. http://dx.doi.org/10.1023/A:1026450103225

Arnett, J. J. (2004). Emerging adulthood: The winding road from the late teens through the twenties. New York: Oxford Press.

Barakat, H. (n.d). The Arab family and the challenge of change. Retrieved from http://acc.teachmideast.org/texts.php?module_id=8\&reading_id=13\&sequence $=3$ 
Berman, W. H., \& Sperling, M. B. (1991). Parental attachment and emotional distress in the transition to college. Journal of Youth and Adolescence, 20, 427-440. http://dx.doi.org/10.1007/BF01537184

Birditt, K. S., Fingerman, K. L., Lefkowitz, E. S., \& Kamp-Dush, C. M. (2008). Parents perceived as peers: Filial maturity in adulthood. Journal of Adult Development, 15, 1-12. http://dx.doi.org/10.1007/s 10804-007-9019-2

Bouchard, G. (2014). How do parents react when their children leave home? An integrative review. Journal of Adult Development, 21(2), 69-79. http://dx.doi.org/10.1007/s 10804-013-9180-8

Braun, V., \& Clarke, V. (2006) Using thematic analysis in psychology. Qualitative Research in Psychology, 3(2), 77-101. http://dx.doi.org/10.1191/1478088706qp063oa

Buhl, H. M. (2007). Well-being and the child-parent relationship at the transition from university to working life. Journal of Adolescent Research, 22, 550-571. http://dx.doi.org/10.1177/0743558407305415

Central Bureau of Statistics. (2015). Families in Israel. http://www.cbs.gov.il/reader/?MIval=cw_usr_view_SHTML\&ID=312

Clarke, E. J., Preston, M., Raksin, J., \& Bengtson, V. L. (1999). Types of conflicts and tensions between older parents and adult children. The Gerontologist, 39, 261-270. http://dx.doi.org/10.1093/geront/39.3.261

Colarusso, C. A., \& Nemiroff, R. A. (1987). Clinical implications of adult development theory. American Journal of Psychiatry, 144, 1263-1270. http://dx.doi.org/10.1177/000306518703500106

Coleman, J. C., \& Brooks, E (2009). Key data on adolescence. Brighton: Trust for the Study of Adolescence.

DeVries, H., Kerrick, S., \& Oetinger, M. (2007). Satisfactions and Regrets of Midlife Parents: A Qualitative Analysis. Journal of Adult Development, 14, 6-15. http://dx.doi.org/10.1007/s 10804-007-9024-5

Dor, A. (2013). Don't stay out late! Mom, I'm twenty-eight: Emerging adults and their parents under one roof. International Journal of Social Science Studies, 1(1), 37-46. http://dx.doi.org/10.11114/ijsss.v li1.35

Dor, A. (2015). Living with my folks: Emerging adults and their parents under one roof. Advances in Social Sciences Research Journal, 2(4), 68-80. http://dx.doi.org/10.14738/assrj.24.1096

Dubas, J. S., \& Petersen, A. C. (1996). Geographical distance from parents and adjustment during adolescence and young adulthood. In J. Graber \& J. Dubas (Eds.), San Francisco, CA: Jossey-Bass, New directions for child development: Leaving home: Understanding the transition to adulthood, 71, 3-20.

Dwairy, M. A. (1998). Cross-cultural counseling: The Arab-Palestinian case. New York: The Haworth Press.

Dwairy, M., \& Achoui, M. (2006). Introduction to three cross-regional research studies on parenting styles. Journal of Cross-Cultural Psychology, 37, 221-229.

El-Haj, M. (1984). Family life style in the Arab society in Israel - Processes of modification and conservation: Nuclear and extended family. In R. Hoch mann (Ed.), Jews and Arabs in Israel. Jerusalem: Hebrew University, Department of high-school teacher training (Hebrew).

Fingerman, K. L., Pitzer, L. M., Chan, W., Birditt, K., Franks, M. M., \& Zarit, S. (2011). Who gets what and why? Help middle-aged adults provide to parents and grown children. Journal of Gerontology Series B: Psychological Sciences \& Social Sciences, 66B(1), 87-98. http://dx.doi.org/10.1093/geronb/gbq009

Furstenberg Jr., F. F. (2010). On a new schedule: Transitions to adulthood and family change. Future of Children, 20, 67-87.

Gautun, H., \& Hagen, K. (2010). How do middle-aged employees combine work with caring for elderly parents? Community, Work \& Family, 13, 393-409. http://dx.doi.org/10.1080/13668800903360625

Gharrah, R. (Ed.) (2013). Arab society in Israel: Population, society, economy. Jerusalem: Van Leer Jerusalem Institute / Hakibbutz Hameuchad Publishing (Hebrew).

Hendry, L. B., \& Kloep, M. (2007). Conceptualizing emerg ing adulthood: Inspecting the emperor's new clothes? Child Development Perspectives, 1, 74-79. http://dx.doi.org/10.1111/j.1750-8606.2007.00017.x

Juang, L. P., \& Silbere isen, R. K. (2001). Family transition for young adult wo men in the context of a changed Germany: Timing, sequence and duration. American Behavioral Scientist, 44, 1899-1917. http://dx.doi.org/10.1177/00027640121958212

Kins, E., Soenens, B., \& Beyers, W. (2011). Why do they have to grow up so fast? Parental separation anxiety and emerging adults' pathology of separation-individuation. Journal of Clinical Psychology, 67, 647-664. http://dx.doi.org/10.1002/jclp.20786 
Kloep, M., \& Hendry, L. B. (2010). Letting go or holding on? Parents' perceptions of their relationships with their children during emerging adulthood. British Journal of Developmental Psychology, 28, 817-834. http://dx.doi.org/10.1348/026151009X480581

Lefkowitz, E. S. (2005). "Things have gotten better": Developmental changes among emerging adults after the transition to university. Journal of Adolescent Research, 20, 40-63. http://dx.doi.org/10.1177/0743558404271236

Mohamed, A., \& Yusuf, A. M. (2011). Somali parent-child conflict in the western world: Some brief reflections. Bildhaan, An International Journal of Somali Studies, 11, 164-173

Morgan, E. M., Thorne, A., \& Zurbriggen, E. L. (2010). A longitudinal study of conversations with parents about sex and dating during ollege. Developmental Psychology,46(1), 139-150. http://dx.doi.org/10.1037/a0016931

Sandelowski, M., \& Barroso J. (2003).) Classifying the Findings in Qualitative Studies. Qualitative Health Research, 13(7), 905-923. http://dx.doi.org/10.1177/1049732303253488

Sarugy, M. (2000). Modernization process and its effect on Arab women's status in Israel. Haifa: Rim (Hebrew).

Settersten Jr., R. A., \& Ray, B. (2010). What's going on with young people today? The long and twisting path to adulthood. Future of Children, 20, 19-41.

Shulman, S., \& Ben-Artzi, E. (2003). Age-related differences in the transition from adolescence to adulthood and links with family relationships. Journal of Adult Development, 10, 217-226. http://dx.doi.org/10.1023/A:1026006025155

Shulman, S., Feldman, B., Blatt, S. J., Coken, O., \& Mahler, A. (2005). Emerg ing adulthood: Age-related tasks and underlying self-process. Journal of Adolescence Research, 20, 577-603. http://dx.doi.org/10.1177/0743558405274913

Smooha, S. (1984). The orientation and politization of the Arab minority in Israel. Haifa: Institute of Middle East Studies, University of Haifa.

Tanner, J. L. (2006). Recentering during emerging adulthood: A critical turning point in life span human development. In J. J. Arnett \& J. L. Tanner (Eds.), Emerging adults in America: Coming of age in the 21 st century, 21-55. Washington, DC: American Psychological Association. http://dx.doi.org/10.1037/11381-002

The Israel democracy institute (2011). Employment among Israeli Arabs. http://en.idi.org.il/analysis/articles/employment-among-israeli-arabs/

U.S. Census Bureau (2011). More young adults are living in their parents' home. Census Bureau Reports. Retrieved from: http://www.census.gov/newsroom/releases/archives/families_households/cb11-183.html

Van Wel, F., Ter Bogt, T., \& Raaijmakers, Q. (2002). Changes in the parental bond and the well-being of adolescents and young adults. Adolescence, 37, 317-333.

Vas sallo, S., Smart, D., \& Price-Roberts on, R. (2009). The roles that parents play in the lives of their young adult children. Family Matters, 82, 8-14. http://www.aifs.gov.au/institute/pubs/fm2009/fm82/sv.pdf

Yanir, I. (2007). Emerging adulthood in the family system: Developmental tasks and family dynamics. Unpublished PH.D dissertation. Haifa University, Israel. (Hebrew).

Youniss, J., \& Smollar, J. (1985). Adolescent relations with mothers, fathers, and friends. Chicago, IL: University Press. http://dx.doi.org/10.1177/0272431685051011

\section{(cc) $\mathrm{EY}$}

This work is licensed under a Creative Commons Attribution 3.0 License. 